\title{
Mediating Effect of Resilience on the Association between Emotional Neglect and Depressive Symptoms
}

\author{
Sang Won Lee, Geum Ye Bae, Hyo-Deog Rim, Seung Jae Lee, \\ Sung Man Chang, Byung-Soo Kim, and Seunghee Won $\bowtie$ \\ Department of Psychiatry, Kyungpook National University Hospital, Daegu, Republic of Korea
}

\begin{abstract}
Objective Previous studies have reported that childhood maltreatment experiences could induce biological and psychological vulnerability in depressive disorders. However, it is still unclear that type-specific effects of childhood maltreatment on psychological resilience, depressive symptoms and interactions among childhood maltreatment experiences, resilience, and depressive symptoms.

Methods A total of 438 medical students were included in the study. The Childhood Trauma Questionnaire-Short Form, the ConnerDavidson Resilience Scale, and the Beck Depression Inventory were used for measuring childhood maltreatment experiences, psychological resilience, and depressive symptoms, respectively. We investigated the effects of childhood maltreatment experiences on resilience and depressive symptoms using correlation analysis. In addition, we analyzed the mediating effect of resilience on the association between childhood maltreatment and symptoms of depression.

Results Among childhood maltreatment, emotional neglect was a significant predictor of the scores of low resilience and high depressive symptoms in both gender groups (all ps<0.05). Furthermore, resilience was found to be a mediator connecting emotional neglect experiences with depressive symptoms.

Conclusion Our results suggest that emotional neglect has detrimental effects on mood and resilience, and clinicians need to focus on the recovery of resilience when they deal with depressive symptoms in victims of childhood maltreatment.
\end{abstract}

Psychiatry Investig 2018;15(1):62-69

Key Words Emotional neglect, Resilience, Depression.

\section{INTRODUCTION}

Experiences of childhood maltreatment (CM) are closely linked with various adult psychopathologies. ${ }^{1,2}$ Among various psychiatric disorders, major depression is one of the most common diseases related to CM. CM negatively affects the lifetime risk as well as the course of depression. ${ }^{3,4}$ Patients with depression and childhood maltreatment reported recurrent and persistent episodes of depression and low response to treatment for depression. ${ }^{3}$

$\mathrm{CM}$ could induce biological and psychological vulnerability in depression. Even in preclinical samples, abusive experiences

Received: May 4, 2017 Revised: July 17, 2017

Accepted: November 7, 2017 Available online: December 14, 2017

$\triangle$ Correspondence: Seunghee Won, MD

Department of Psychiatry, Kyungpook National University Hospital, 130 Dongduk-ro, Jung-gu, Daegu 41944, Republic of Korea

Tel: +82-53-420-5751, Fax: +82-53-420-5361, E-mail: wonsh864@knu.ac.kr

(a) This is an Open Access article distributed under the terms of the Creative Commons Attribution Non-Commercial License (http://creativecommons.org/licenses/by$\mathrm{nc} / 4.0$ ) which permits unrestricted non-commercial use, distribution, and reproduction in any medium, provided the original work is properly cited. damage the brain structure and function related to emotion processing. The main fiber tracts linking prefrontal and subcortical regions are altered by experiences of emotional abuse. ${ }^{5,6}$ $\mathrm{CM}$ experiences induce hyper-reactivity of the amygdala to negative emotional stimuli. ${ }^{7-12}$ Furthermore, aberrant functional connectivity between the ventromedial prefrontal cortex and the amygdala were reported in subjects with CM experiences. ${ }^{12,13}$ Moreover, CM increases maladaptive psychological and behavioral problems, such as unusual aggression, low self-esteem, withdrawal from family and friends, and self-destructive behaviors. ${ }^{14}$ Therefore, these biological and psychological changes make the victims of CM more vulnerable to mood problems.

Although a relationship between CM and depression has been established, the role of psychological resilience on the onset and course of depression is still unclear. The term "resilience" has begun to attract attention because recent studies reported protective effects of psychological resilience on aggravation of psychiatric symptoms in subjects with CM experiences including post-traumatic stress disorder, depression, and sui- 
cidal behaviors. ${ }^{15-20}$ However, to the best of our knowledge, only three studies reported moderating effects of resilience on depressive symptoms, ${ }^{15,21,22}$ and differential effects between types of $\mathrm{CM}$ were not evaluated in these studies. The effects of $\mathrm{CM}$ on depressive symptoms and resilience can be differed among types of CM. While all types of CM are involved in the development of depression, ${ }^{21,23}$ several studies represented that emotional abuse and neglect have a close relationship with depressive symptoms than other types of abuse. ${ }^{24,25}$ In addition, only emotional abuse, emotional neglect and sexual abuse showed negative relationship with resilience. ${ }^{26}$ Therefore, further investigation is needed to understand type-specific effects of CM on psychological resilience, depressive symptoms and interactions among $\mathrm{CM}$, resilience, and depressive symptoms.

In this study, we aimed to clarify the effects of CM on resilience and depressive symptoms. In addition, we verified whether the CM type-specific effect exists. In addition, we analyzed the mediating effect of resilience on the association between $\mathrm{CM}$ and symptoms of depression. We assumed that the $\mathrm{CM}$ experiences, especially emotional type of $\mathrm{CM}$, have negative effects on psychological resilience and depressive symptoms, and low resilience could lead the victims of CM to a depressive state.

\section{METHODS}

\section{Participants}

All subjects were graduate medical students at the Kyungpook National University School of Medicine in South Korea. The Kyungpook National University School of Medicine conducted mental health assessment for students annually from 2009, and the data used in this study were drawn from first- and third-year students in 2012 and 2013. Among 440 students, 2 subjects were excluded from our analysis due to missing values. Therefore, in the final analysis, the data of 438 graduate students [ 265 male subjects and 173 female subjects; mean age $(\mathrm{SD})=25.2$ (2.5) years] were included. All subjects voluntarily participated and provided written consent, and this study was approved by the Ethics Committee of the Kyungpook National University School of Medicine (IRB No. 2013-05-026-001).

\section{Measures}

\section{Childhood Trauma Questionnaire-Short Form}

The Childhood Trauma Questionnaire-Short Form (CTQ$\mathrm{SF}$ ) is a self-report questionnaire with 28 -items developed to assess the severity of 5 types of maltreatment experiences, such as emotional abuse, physical abuse, sexual abuse, emo- tional neglect, and physical neglect during childhood and adolescence. ${ }^{27}$ The severity of each maltreatment experience is measured through a 5-point, Likert-type scale ranging from never true (score $=1)$ to very often true $($ score $=5)$. The CTQSF showed good to excellent internal consistency both in clinical and community samples. ${ }^{27,28}$ In this study, the Korean version of CTQ-SF was applied to assess the subjects' maltreatment experiences. The Korean version of CTQ-SF represented excellent internal consistency (Cronbach's alpha $>0.9)$ and high test-retest reliability (Pearson $\mathrm{r}>0.8$ ). ${ }^{29}$

\section{Conner-Davidson Resilience Scale}

The Conner-Davidson Resilience Scale (CD-RISC) is a questionnaire to evaluate psychological resilience related to coping skills on stressful events. ${ }^{30}$ This questionnaire consists of 25-items, and each item is rated using a self-reported 5-point scale (0 to 4). A higher score indicates greater psychological resilience. In factor analysis, the CD-RISC was divided into 5 sub-factors: hardness, persistence, optimism, support, and being spiritual. High reliability and validity of CD-RISC has been confirmed in a community sample, primary care patients, and psychiatric patients. ${ }^{30}$ The Korean version of CD-RISC was developed in 2010 with excellent internal consistency (Cronbach's alpha $>0.9$ ) and high test-retest reliability (Pearson $r>0.9$ ) in samples comprising university students, nurses, and firefighters. ${ }^{31}$ Furthermore, reliability and validity were verified in another study with general population and psychiatric outpatients. 32

\section{Beck Depression Inventory}

Depressive symptoms in the subjects were measured using the Beck Depression Inventory (BDI). The cognitive, behavior$\mathrm{al}$, affect, and somatic components of depressive symptoms are included in the BDI, a 21-item, self-report questionnaire. ${ }^{33}$ Using the BDI, the intensity of depressive symptoms in the week before the examination was measured. The Korean version of the BDI was standardized and showed a good internal consistency in depressed group (Cronbach's alpha $=0.85$ ). ${ }^{34}$

\section{Statistical analysis}

To evaluate effect of CM on depressive symptoms, our subjects were divided into two groups based on median score of CTQ-SF (high CM and low CM). T-test was used to measure the differences in scores of BDI between high CM and low $\mathrm{CM}$ groups. Also, binary logistic regression analysis was conducted to assess the differences in risk of clinically significant depressive symptoms (the scores of BDI 16 or above) between two groups. Also, we checked normality of the data using skewness and kurtosis. To assess the relationships between current depressive symptoms, resilience, and childhood trau- 
ma experiences, partial correlation analysis was applied (covariate: gender). In addition, multiple regression analysis was used to investigate the effects of each maltreatment experience on depressive symptoms and psychological resilience because various maltreatment experiences could influence each other. We analyzed the whole group after controlling for gender as well as male and female groups to evaluate the gender effects in multiple regression analysis. SPSS software (version 18; SPSS Inc., Chicago, IL, USA) was used in these analyses.

In addition, mediation analysis using structural equation modeling (SEM) was performed to determine the associations between childhood trauma experiences, resilience, and depressive symptoms. Based on the results of multiple regression analysis, we selected the independent variable (childhood trauma experiences) that is a significant predictor of the dependent variable (depressive symptoms) and the mediator (resilience), respectively. The mediating effects of resilience on predicting depressive symptoms using traumatic childhood experiences were evaluated using SEM analysis. Furthermore, an additional analysis including gender effects as a covariate was conducted. The significances on SEM analysis were supported by 1,000 times bootstrapping. AMOS software (version 18; SPSS Inc.) was applied for mediation analysis.

\section{RESULTS}

\section{Group comparison analysis and Normality test}

High CM group showed high scores of BDI compared to low CM group (7.4 in high CM and 4.9 in low CM groups, $\mathrm{p}<0.001)$. Also, high CM group represented high chance to have clinically significant depressive symptoms (odds ratio=
3.82, 95\% $\mathrm{CI}=1.50-9.71, \mathrm{p}=0.005)$. In normality test using skewness $(\mathrm{S})$ and kurtosis $(\mathrm{K})$, several data represented highly skewed results [Emotional abuse: 2.8 (S) and 12.2 (K); Emotional neglect: $1.3(\mathrm{~S})$ and $2.2(\mathrm{~K})$; Sexual abuse: $5.4(\mathrm{~S})$ and $35.0(\mathrm{~K})$; Physical abuse: $3.4(\mathrm{~S})$ and $15.1(\mathrm{~K})$; Physical neglect: $1.0(\mathrm{~S})$ and $0.1(\mathrm{~K})$; CD-RISC: $-0.4(\mathrm{~S})$ and $1.6(\mathrm{~K})$; BDI: 1.7 $(\mathrm{S})$ and $4.4(\mathrm{~K})]$. Therefore, we conducted additional analyses using transformed data applying natural logarithm transformation, and transformed data showed better results in skewness and kurtosis (except CD-RISC) (Supplementary Materials in the online-only Data Supplement).

\section{Correlation analysis}

In correlation analysis, childhood maltreatment experiences, except sexual abuse, have significant positive relationships with depressive symptoms in both genders (all ps<0.05). Experiences of physical abuse experiences in men and emotional abuse in women showed significant relationship with low resilience and high depressive symptoms (all ps<0.05). Among childhood maltreatment experiences, emotional neglect represented high correlations with total scores, scores of subscales (except spiritual) of CD-RISC, and the scores of the BDI in both genders (all ps<0.01). Detailed results are described in Table 1.

\section{Multiple regression analysis}

Emotional neglect was a significant predictor for low CDRISC scores after adjusting for the effects of other types of maltreatment in male subjects, female subjects, and all groups (all ps $<0.001$ ). Furthermore, physical abuse was negatively associated with the scores of CD-RISC in the male group $(\mathrm{p}<$

Table 1. Pearson correlation coefficients among traumatic childhood experiences, resilience, and depressive symptoms

\begin{tabular}{|c|c|c|c|c|c|c|c|}
\hline & \multicolumn{6}{|c|}{ CD-RISC } & \multirow{2}{*}{$\frac{\text { BDI }}{\text { Total }}$} \\
\hline & Hardness & Persistence & Optimism & Support & Spiritual & Total & \\
\hline \multicolumn{8}{|l|}{ Male $(\mathrm{N}=265)$} \\
\hline Emotional abuse & -0.10 & -0.10 & -0.00 & $-0.14^{*}$ & 0.07 & -0.09 & $0.15^{*}$ \\
\hline Emotional neglect & $-0.23^{* * *}$ & $-0.31^{* * *}$ & $-0.22^{* * *}$ & $-0.30^{* * *}$ & 0.02 & $-0.29 * * *$ & $0.21^{* * *}$ \\
\hline Sexual abuse & -0.00 & -0.05 & 0.01 & -0.05 & $0.20^{* *}$ & 0.00 & 0.09 \\
\hline Physical abuse & $-0.14^{*}$ & $-0.16^{* *}$ & -0.06 & $-0.19^{* *}$ & -0.06 & $-0.14^{*}$ & $0.26^{* * *}$ \\
\hline Physical neglect & -0.05 & -0.09 & -0.04 & $-0.18^{* *}$ & 0.02 & -0.08 & $0.14^{*}$ \\
\hline \multicolumn{8}{|l|}{ Female $(\mathrm{N}=173)$} \\
\hline Emotional abuse & $-0.32^{* * *}$ & $-0.18^{*}$ & $-0.19^{*}$ & $-0.19^{*}$ & 0.07 & $-0.22^{* *}$ & $0.41^{* * *}$ \\
\hline Emotional neglect & $-0.39 * * *$ & $-0.30^{* * *}$ & $-0.44^{* * *}$ & $-0.41^{* * *}$ & 0.11 & $-0.47 * * *$ & $0.27^{* * *}$ \\
\hline Sexual abuse & $-0.20^{* *}$ & -0.11 & -0.15 & -0.11 & -0.04 & $-0.17^{*}$ & 0.11 \\
\hline Physical abuse & -0.05 & -0.14 & -0.05 & -0.05 & -0.03 & -0.07 & $0.25^{* *}$ \\
\hline Physical neglect & $-0.22^{* *}$ & $-0.23^{* *}$ & $-0.26^{* * *}$ & $-0.28^{* * *}$ & 0.05 & $-0.30 * * *$ & $0.16^{*}$ \\
\hline
\end{tabular}

All correlation coefficients were transformed using Fisher r-to-z transformation. ${ }^{*} \mathrm{p}<0.05,{ }^{* *} \mathrm{p}<0.01,{ }^{* * *} \mathrm{p}<0.001$. CD-RISC: Connor-Davidson Resilience Scale, BDI: Beck Depression Inventory 
Table 2. Multiple regression analysis for explaining resilience scores (CD-RISC) using the quantity of abusive experiences in male group, female groups, and all groups

\begin{tabular}{|c|c|c|c|c|c|c|c|}
\hline & \multicolumn{2}{|c|}{$\begin{array}{c}\text { Unstandardized } \\
\text { Coefficients }\end{array}$} & \multirow{2}{*}{$\begin{array}{c}\begin{array}{c}\text { Standardized } \\
\text { Coefficients }\end{array} \\
\text { Beta }\end{array}$} & \multirow[t]{2}{*}{$\mathrm{T}$} & \multirow{2}{*}{$\mathrm{p}$} & \multirow[t]{2}{*}{$\mathrm{R}^{2}$} & \multirow[t]{2}{*}{$\mathrm{F}$} \\
\hline & Beta $(95 \% \mathrm{CI})$ & SE & & & & & \\
\hline Male $(\mathrm{N}=265)$ & & & & & & 0.10 & $5.74^{* * *}$ \\
\hline (Constant) & $72.56(60.88-84.23)$ & 5.93 & & 12.24 & 0.00 & & \\
\hline Emotional abuse & $0.72(-0.86-2.29)$ & 0.80 & 0.07 & 0.90 & 0.37 & & \\
\hline Emotional neglect*** & $-1.13(-1.63--0.64)$ & 0.25 & -0.32 & -4.50 & 0.00 & & \\
\hline Sexual abuse & $1.18(-1.04-3.40)$ & 1.13 & 0.07 & 1.05 & 0.30 & & \\
\hline Physical abuse* & $-1.03(-1.93--0.12)$ & 0.46 & -0.16 & -2.24 & 0.03 & & \\
\hline Physical neglect & $0.46(-0.30-1.22)$ & 0.39 & 0.08 & 1.19 & 0.24 & & \\
\hline Female $(\mathrm{N}=173)$ & & & & & & 0.22 & $9.28^{* * *}$ \\
\hline (Constant) & $89.83(79.37-100.29)$ & 5.30 & & 16.96 & 0.00 & & \\
\hline Emotional abuse & $-0.79(-2.05-0.48)$ & 0.64 & -0.11 & -2.05 & 0.22 & & \\
\hline Emotional neglect*** & $-1.31(-1.87--0.74)$ & 0.29 & -0.36 & -4.57 & 0.00 & & \\
\hline Sexual abuse & $-0.49(-2.22-1.24)$ & 0.88 & -0.04 & -0.56 & 0.58 & & \\
\hline Physical abuse & $0.27(-0.76-1.30)$ & 0.52 & 0.04 & 0.52 & 0.60 & & \\
\hline Physical neglect & $-0.56(-1.42-0.31)$ & 0.44 & -0.10 & -1.28 & 0.30 & & \\
\hline Whole $(\mathrm{N}=438)$ & & & & & & 0.12 & $9.89^{* * *}$ \\
\hline (Constant) & $83.94(75.61-92.27)$ & 4.24 & & 19.80 & 0.00 & & \\
\hline Gender & $-0.97(-3.49-1.54)$ & 1.28 & -0.04 & -0.76 & 0.45 & & \\
\hline Emotional abuse & $-0.19(-1.18-0.79)$ & 0.50 & -0.02 & -0.38 & 0.70 & & \\
\hline Emotional neglect*** & $-1.16(-1.54--0.79)$ & 0.19 & -0.33 & -6.17 & 0.00 & & \\
\hline Sexual abuse & $0.08(-1.31-1.46)$ & 0.70 & 0.01 & 0.11 & 0.92 & & \\
\hline Physical abuse & $-0.37(-1.04-0.31)$ & 0.34 & -0.06 & -1.07 & 0.28 & & \\
\hline Physical neglect & $0.01(-0.57-0.58)$ & 0.29 & 0.00 & 0.02 & 0.99 & & \\
\hline
\end{tabular}

${ }^{*} \mathrm{p}<0.05,{ }^{* * *} \mathrm{p}<0.001$. CD-RISC: Connor-Davidson Resilience Scale

0.05) (Table 2).

In addition, we observed that the higher the scores for emotional neglect were, the greater were the depressive symptoms in both male and female groups (all ps<0.05). While physical abuse experiences were a significant predictor of depressive symptoms in the male group ( $\mathrm{p}<0.01)$, the female group represented significant effects of emotional abuse, and not physical abuse, on depressive symptoms $(\mathrm{p}<0.001)$ (Table 3$)$.

To compensate distribution issues, we conducted additional multiple regression analysis using values that were transformed using natural logarithm, and the results were similar with analysis using raw data (Supplementary Table 1 in the online-only Data Supplement).

\section{Mediation analysis using structural equation modeling (SEM)}

The scores of emotional neglect were selected as independent variables in mediating regression analyses because emotional neglect had a significant relationship with low resilience and high depressive symptoms both in male and female groups. The scores of emotional neglect significantly predicted the scores of depressive symptoms and those of resilience (all ps $<0.001)$. However, a significant path connecting emotional neglect and depressive symptoms disappeared in the analysis with no covariate or decreased $(\mathrm{p}<0.05)$ in the analysis with gender covariate when the mediating effects of resilience were included in the SEM analysis (Figure 1). In the model with gender covariance, standardized direct effect of emotional neglect on the depressive symptoms was 0.09 (95\% CI=0.00$0.19, \mathrm{p}<0.05)$; standardized indirect effect of resilience on depressive symptoms was 0.14 (95\% $\mathrm{CI}=0.10-0.19, \mathrm{p}=0.001)$. The model represented perfect fit indices since the model was saturated $\left[\chi^{2}(0)=0.00, \mathrm{GFI}=1, \mathrm{CFI}=1, \mathrm{NFI}=1\right]$.

We conducted additional SEM analysis using values that were transformed using natural logarithm, and the results were similar with analysis using raw data (Supplementary Figure 1A in the online-only Data Supplement). It was also examined whether measurements were similar across the types of abuse. Physical abuse in male and emotional abuse in female were selected since significant relationships with cur- 
Table 3. Multiple regression analysis for explaining depression scores (BDI) using the quantity of abusive experiences in male group, female group, and all groups

\begin{tabular}{|c|c|c|c|c|c|c|c|}
\hline & \multicolumn{2}{|c|}{$\begin{array}{c}\text { Unstandardized } \\
\text { Coefficients }\end{array}$} & \multirow{2}{*}{$\begin{array}{c}\text { Standardized } \\
\text { Coefficients }\end{array}$} & \multirow[t]{2}{*}{$\mathrm{T}$} & \multirow[t]{2}{*}{$\mathrm{p}$} & \multirow[t]{2}{*}{$\mathrm{R}^{2}$} & \multirow[t]{2}{*}{$\mathrm{F}$} \\
\hline & Beta $(95 \% \mathrm{CI})$ & SE & & & & & \\
\hline Male $(\mathrm{N}=265)$ & & & & & & 0.09 & $5.37^{* * *}$ \\
\hline (Constant) & $0.81(-3.40-502)$ & 2.14 & & 0.38 & 0.71 & & \\
\hline Emotional abuse & $-0.12(-0.69-0.45)$ & 0.20 & -0.03 & -0.43 & 0.67 & & \\
\hline Emotional neglect* & $0.21(0.03-0.38)$ & 0.09 & 0.16 & 2.27 & 0.02 & & \\
\hline Sexual abuse & $-0.10(-0.90-0.70)$ & 0.41 & -0.02 & -0.25 & 0.81 & & \\
\hline Physical abuse ${ }^{* *}$ & $0.55(0.23-0.88)$ & 0.17 & 0.24 & 3.35 & 0.00 & & \\
\hline Physical neglect & $0.09(-0.19-0.36)$ & 0.14 & 0.04 & 0.64 & 0.52 & & \\
\hline Female $(\mathrm{N}=173)$ & & & & & & 0.18 & $7.31^{* * *}$ \\
\hline (Constant) & $-2.26(-7.12-2.61)$ & 2.47 & & -0.92 & 0.36 & & \\
\hline Emotional abuse ${ }^{* * *}$ & $1.06(0.47-1.65)$ & 0.30 & 0.32 & 3.55 & 0.00 & & \\
\hline Emotional neglect* & $0.27(0.01-0.53)$ & 0.13 & 0.17 & 2.03 & 0.04 & & \\
\hline Sexual abuse & $-0.13(-0.93-0.68)$ & 0.41 & -0.02 & -0.31 & 0.76 & & \\
\hline Physical abuse & $0.12(-0.36-0.60)$ & 0.294 & 0.04 & 0.49 & 0.63 & & \\
\hline Physical neglect & $0.03(-0.37-0.44)$ & 0.20 & 0.01 & 0.16 & 0.87 & & \\
\hline Whole $(\mathrm{N}=438)$ & & & & & & 0.13 & $10.91^{* * *}$ \\
\hline (Constant) & $-3.19(-6.51-0.14)$ & 1.69 & & -1.88 & 0.60 & & \\
\hline Gender** & $1.37(0.36-2.37)$ & 0.51 & 0.12 & 2.68 & 0.01 & & \\
\hline Emotional abuse ${ }^{* *}$ & $0.55(0.16-0.94)$ & 0.20 & 0.16 & 2.75 & 0.01 & & \\
\hline Emotional neglect** & $0.21(0.06-0.36)$ & 0.08 & 0.15 & 2.77 & 0.01 & & \\
\hline Sexual abuse & $-0.13(-0.69-0.42)$ & 0.28 & -0.02 & -0.69 & 0.42 & & \\
\hline Physical abuse* & $0.35(0.08-0.62)$ & 0.14 & 0.14 & 2.57 & 0.01 & & \\
\hline Physical neglect & $0.11(-0.12-0.34)$ & 0.12 & 0.05 & 0.95 & 0.34 & & \\
\hline
\end{tabular}

${ }^{*} \mathrm{p}<0.05,{ }^{* *} \mathrm{p}<0.01,{ }^{* * *} \mathrm{p}<0.001$. BDI: Beck Depression Inventory

rent depressive symptoms were reported in multiple regression analysis. Indirect effects of resilience on depressive symptoms were significant in both physical abuse in male and emotional abuse in female (Supplementary Figure 1B and C in the online-only Data Supplement).

\section{DISCUSSION}

Our results showed that $\mathrm{CM}$ experiences are significantly related to psychological resilience and depressive symptoms. Among various $\mathrm{CM}$ experiences, emotional neglect is a consistent and significant factor for predicting low scores of resilience and high scores of depressive symptoms in both genders. In addition, we found that resilience could be a mediator in connecting emotional neglect experiences with depressive symptoms. These results suggest that emotional neglect, which is an easily neglected form of $\mathrm{CM}$, has considerable effects on psychological resilience that can lead people to depression.

While child neglect is the most prevalent type of CM, its effects seem to be neglected in previous studies. Category of neglect had the highest percentage (about 60\%) of CM experiences in the United States. ${ }^{35}$ In a recent meta-analysis, the overall estimated prevalence rates were $16.3 \%$ for physical neglect and $18.4 \%$ for emotional neglect. ${ }^{36}$ Emotional neglect is characterized by the acts ignoring the child's basic emotional needs, such as insufficient or no emotional interaction between parents and the child. ${ }^{37}$ The consequences of emotional neglect should not be overlooked. Emotional neglect experiences were strongly linked with symptoms of anxiety, depression, and suicidal attempt in recent meta-analysis. ${ }^{38}$ Also, several recent studies try to discover the possible mediators between emotional neglect and depression. In college students, emotional neglect was related to symptoms of depression, anxiety, and depression and was mediated by specific schemas including shame. ${ }^{39}$ Dysfunction in ventral striatum $^{40}$ and specific emotional regulation strategy, such as behavioral avoidance ${ }^{41}$ can be mediators between emotional neglect and depression. Also, the neglect experiences can be associated with a risky sexual behavior, ${ }^{42}$ a diminished economic well-being, ${ }^{43}$ a dysfunctional attachment style, ${ }^{44}$ and 


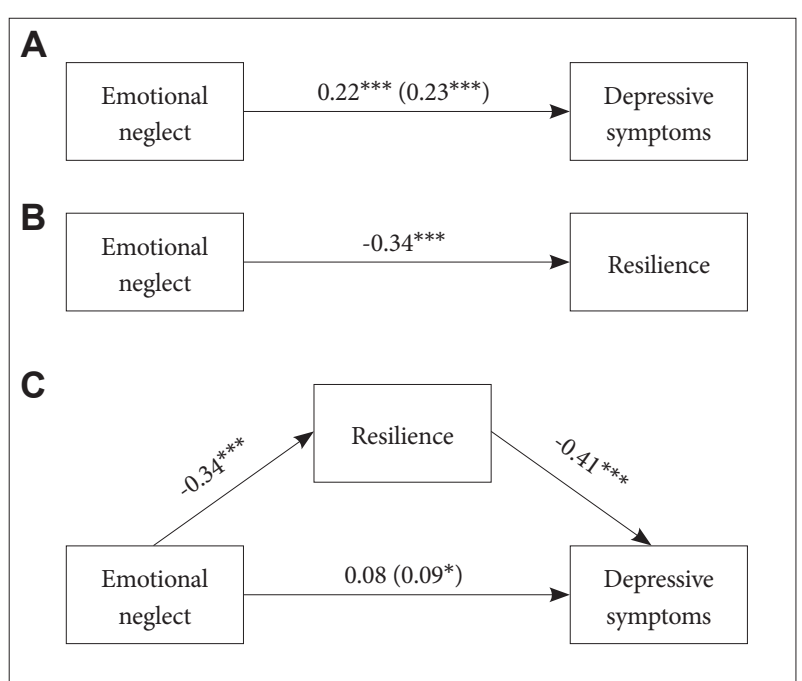

Figure 1. The mediating effect of resilience on the relationship between previous emotional neglect experiences and current depressive symptoms. (A) and (B) represent a direct effect of emotional neglect on depressive symptoms and resilience, respectively. The mediating effect of resilience is shown in (C). The changed values after controlling for gender were described within the bracket. Total scores of CD-RISC and BDI are used for resilience and depressive symptoms, respectively. ${ }^{*} p<0.05,{ }^{* * *} p<$ 0.001. CD-RISC: Connor-Davidson Resilience Scale, BDI: Beck Depression Inventory.

an increased violence risk. ${ }^{45}$

In our results, only emotional neglect was a consistent and significant factor showing relationships with low resilience scores and high depressive symptoms scores in both genders. There were two possible explanations for these results. First, the medical school is considered one of the most competitive departments for admission in South Korea. Previous studies reported CM experiences could lead to impaired school performance including low grade point average. ${ }^{46,47}$ Adolescents with CM experiences, mostly, physical abuse or sexual abuse, showed lower neurocognitive functioning. ${ }^{48}$ Severe physical abuse experiences was associated with low education years. ${ }^{49}$ Therefore, severe cases of CM might be excluded from our samples. We could predict the prevalence rates of CM using original cutoff scores for "moderate to severe" exposure..$^{50} \mathrm{In}$ our study, emotional neglect (7.8\%) and physical neglect (14.2\%) were the two most common types of CM (physical abuse: $6.2 \%$, sexual abuse $3.4 \%$, and emotional abuse: $0.7 \%$ ). Although population based studies reported large variation in prevalence rates of $\mathrm{CM}$ experiences, ${ }^{51}$ overall prevalence rates of CM experiences were relatively low in our study compared to other previous studies. ${ }^{52-55}$ In recent studies using meta-analysis, the overall estimated prevalence rates were $12.7 \%$ for sexual abuse, ${ }^{56} 26.7 \%$ for emotional abuse, ${ }^{57}$ and $17.7 \%$ for physical abuse. ${ }^{58}$ Also, CTQ-SF scores of physical abuse, sexual abuse, and emotional abuse showed high skewness and kurtosis in normality test. Therefore, our subjects' character- istics may have affected our results. Second, the emotional type of CM could have dominantly affected depressive symptoms. Emotional type of $\mathrm{CM}$ has been reported to have a close relationship with depressive symptoms than other types of abuse. ${ }^{24,25}$ Emotional abuse and neglect were significant predictors of depressive disorders after controlling for sexual and physical abuse in psychiatric outpatients. ${ }^{25}$ The effects of emotional abuse could be underestimated due to the very low prevalence $(0.7 \%)$, and finally, emotional neglect appears as a significant factor while the prevalence of physical neglect was relatively high. In our study, female reported significantly high scores in emotional abuse experiences compared to male $(\mathrm{t}=$ -3.37, $\mathrm{p}=0.001$ ), and emotional abuse experiences were important factors related to low resilience and high depressive symptoms in female. These results support the effect of emotional type of $\mathrm{CM}$ on depressive symptoms.

Furthermore, the results of mediation analysis showed resilience may have mediating effects on the association between $\mathrm{CM}$ and depressive symptoms. The meaning of resilience is rather vague and hard to define in a sentence. Resilience is a multidimensional construct containing the meaning of the capacity for, the process of, or the outcome of successful adaptation despite threatening circumstances. ${ }^{59}$ Resilience can be the process of effectively mobilizing individual and environmental resources to manage in the face of distressful or traumatic events. ${ }^{60}$ Our results represented that $\mathrm{CM}$ experiences might inhibit the growth of individual resilience, and low resilience might mediate depressive symptoms related to CM. A recent study suggests that resilience could be a protective factor against developing major depressive disorder in patients with $\mathrm{CM}$ experiences and even in subjects without CM experiences. ${ }^{21}$ Our results suggest that increasing resilience can be an important factor to prevent or treat depression in patients with CM experiences.

There are several limitations of the study to be considered. First, our study is a cross-sectional design. Mediation analysis is more acceptable for prospective studies than cross-sectional studies, and our results could not determine a definite causal relationship among $\mathrm{CM}$, resilience, and depressive symptoms. The results should be interpreted in a cautious manner. However, our results could inform future studies on the effects of $\mathrm{CM}$ on resilience and depressive symptoms. Second, only medical students were included in our study. High level of intellectual functioning may be related to high resilience, ${ }^{61}$ and our samples represented low rate of CM experiences. Therefore, our results are hard to generalize. However, there is a lack of study considering the effects of emotional neglect and its relationship with resilience. Also, our results suggest that the need for careful investigation about emotional neglect experiences in highly-educated group. Furthermore, 
in medical students, depressive symptoms are highly prevalent, and it could be related to functional impairment in professional and academic skills. ${ }^{62}$ Medical students may be reluctant to seek care due to fear of academic jeopardy ${ }^{63}$ or concerns about confidentiality. ${ }^{64}$ Therefore, considering the influence of physicians on our health care system, verifying the effects of $\mathrm{CM}$ on psychological resilience and depressive symptoms in medical students can be important. Third, the scores of CTQ-SF were measured based on autobiographical memory that could be easily biased in case of traumatic events. ${ }^{65}$ Also, depressive subjects tend to focus on negative memory, and negatively appraise previous experiences. ${ }^{66,67}$ Further studies with prospective and population-based design are needed to compensate our limitations.

Despite these limitations, our study showed the detrimental effects of emotional neglect on resilience and how resilience mediate the association between CM experiences and depressive symptoms. These results indicate the need for a careful consideration of emotional neglect experiences and providing increased attention to enhancing resilience for alleviating symptoms of depression.

\section{Supplementary Materials}

The online-only Data Supplement is available with this article at https://doi.org/10.4306/pi.2018.15.1.62.

\section{Acknowledgments}

This research was supported by Kyungpook National University Research Fund, 2015.

\section{REFERENCES}

1. Brewin CR, Andrews B, Valentine JD. Meta-analysis of risk factors for posttraumatic stress disorder in trauma-exposed adults. J Consult Clin Psychol 2000;68:748-766.

2. Kessler RC, McLaughlin KA, Green JG, Gruber MJ, Sampson NA, Zaslavsky AM, et al. Childhood adversities and adult psychopathology in the WHO World Mental Health Surveys. Br J Psychiatry 2010;197: 378-385.

3. Nanni V, Uher R, Danese A. Childhood maltreatment predicts unfavorable course of illness and treatment outcome in depression: a metaanalysis. Am J Psychiatry 2012;169:141-151.

4. Bernet CZ, Stein MB. Relationship of childhood maltreatment to the onset and course of major depression in adulthood. Depress Anxiety 1999;9:169-174.

5. Eluvathingal TJ, Chugani HT, Behen ME, Juhasz C, Muzik O, Maqbool $\mathrm{M}$, et al. Abnormal brain connectivity in children after early severe socioemotional deprivation: a diffusion tensor imaging study. Pediatrics 2006;117:2093-2100.

6. Choi J, Jeong B, Rohan ML, Polcari AM, Teicher MH. Preliminary evidence for white matter tract abnormalities in young adults exposed to parental verbal abuse. Biol Psychiatry 2009;65:227-234.

7. Tottenham N, Hare TA, Millner A, Gilhooly T, Zevin JD, Casey BJ. Elevated amygdala response to faces following early deprivation. Dev Sci 2011;14:190-204.

8. Maheu FS, Dozier M, Guyer AE, Mandell D, Peloso E, Poeth K, et al. A preliminary study of medial temporal lobe function in youths with a history of caregiver deprivation and emotional neglect. Cogn Affect
Behav Neurosci 2010;10:34-49.

9. Dannlowski U, Stuhrmann A, Beutelmann V, Zwanzger P, Lenzen T, Grotegerd D, et al. Limbic scars: long-term consequences of childhood maltreatment revealed by functional and structural magnetic resonance imaging. Biol Psychiatry 2012;71:286-293.

10. Dannlowski U, Kugel H, Huber F, Stuhrmann A, Redlich R, Grotegerd D, et al. Childhood Maltreatment is Associated with an Automatic Negative Emotion Processing Bias in the Amygdala. Human Brain Mapp 2013;34:2899-2909.

11. van Harmelen AL, van Tol MJ, Demenescu LR, van der Wee NJ, Veltman DJ, Aleman A, et al. Enhanced amygdala reactivity to emotional faces in adults reporting childhood emotional maltreatment. Soc Cogn Affect Neurosci 2013;8:362-369.

12. Lee SW, Yoo JH, Kim KW, Lee JS, Kim D, Park H, et al. Aberrant function of frontoamygdala circuits in adolescents with previous verbal abuse experiences. Neuropsychologia 2015;79:76-85.

13. Burghy CA, Stodola DE, Ruttle PL, Molloy EK, Armstrong JM, Oler JA, et al. Developmental pathways to amygdala-prefrontal function and internalizing symptoms in adolescence. Nat Neurosci 2012;15: 1736-1741.

14. Al Odhayani A, Watson WJ, Watson L. Behavioural consequences of child abuse. Can Fam Physician 2013;59:831-836.

15. Wingo AP, Wrenn G, Pelletier T, Gutman AR, Bradley B, Ressler KJ. Moderating effects of resilience on depression in individuals with a history of childhood abuse or trauma exposure. J Affect Disord 2010; 126:411-414.

16. Alim TN, Graves E, Mellman TA, Aigbogun N, Gray E, Lawson W, et al. Trauma exposure, posttraumatic stress disorder and depression in an African-American primary care population. J Natl Med Assoc 2006; 98:1630-1636.

17. Collishaw S, Pickles A, Messer J, Rutter M, Shearer C, Maughan B. Resilience to adult psychopathology following childhood maltreatment: evidence from a community sample. Child Abuse Negl 2007;31:211-229.

18. Campbell-Sills L, Cohan SL, Stein MB. Relationship of resilience to personality, coping, and psychiatric symptoms in young adults. Behav Res Ther 2006;44:585-599.

19. Wrenn GL, Wingo AP, Moore R, Pelletier T, Gutman AR, Bradley B, et al. The effect of resilience on posttraumatic stress disorder in traumaexposed inner-city primary care patients. J Natl Med Assoc 2011; 103:560-566.

20. Roy A, Carli V, Sarchiapone M. Resilience mitigates the suicide risk associated with childhood trauma. J Affect Disord 2011;133:591-594.

21. Schulz A, Becker M, Van der Auwera S, Barnow S, Appel K, Mahler J, et al. The impact of childhood trauma on depression: does resilience matter? Population-based results from the Study of Health in Pomerania. J Psychosom Res 2014;77:97-103.

22. Sexton MB, Hamilton L, McGinnis EW, Rosenblum KL, Muzik M. The roles of resilience and childhood trauma history: main and moderating effects on postpartum maternal mental health and functioning. J Affect Disord 2015;174:562-568.

23. Negele A, Kaufhold J, Kallenbach L, Leuzinger-Bohleber M. Childhood Trauma and Its Relation to Chronic Depression in Adulthood. Depress Res Treat 2015;2015:650804.

24. Gibb BE, Chelminski I, Zimmerman M. Childhood emotional, physical, and sexual abuse, and diagnoses of depressive and anxiety disorders in adult psychiatric outpatients. Depress Anxiety 2007;24:256-263.

25. Spertus IL, Yehuda R, Wong CM, Halligan S, Seremetis SV. Childhood emotional abuse and neglect as predictors of psychological and physical symptoms in women presenting to a primary care practice. Child Abuse Negl 2003;27:1247-1258.

26. Kesebir S, Unubol B, Tatlidil Yaylaci E, Gundogar D, Unubol H. Impact of childhood trauma and affective temperament on resilience in bipolar disorder. Int J Bipolar Disord 2015;3:3.

27. Bernstein DP, Stein JA, Newcomb MD, Walker E, Pogge D, Ahluvalia T, et al. Development and validation of a brief screening version of the 
Childhood Trauma Questionnaire. Child Abuse Negl 2003;27:169-190.

28. Scher CD, Stein MB, Asmundson GJ, McCreary DR, Forde DR. The childhood trauma questionnaire in a community sample: psychometric properties and normative data. J Trauma Stress 2001;14:843-857.

29. Kim D, Park SC, Yang H, Oh DH. Reliability and validity of the korean version of the childhood trauma questionnaire-short form for psychiatric outpatients. Psychiatry Investig 2011;8:305-311.

30. Connor KM, Davidson JR. Development of a new resilience scale: the Connor-Davidson Resilience Scale (CD-RISC). Depress Anxiety 2003; 18:76-82.

31. Baek HS, Lee KU, Joo EJ, Lee MY, Choi KS. Reliability and validity of the korean version of the connor-davidson resilience scale. Psychiatry Investig 2010;7:109-115.

32. Jung YE, Min JA, Shin AY, Han SY, Lee KU, Kim TS, et al. The Korean version of the Connor-Davidson Resilience Scale: an extended validation. Stress Health 2012;28:319-326.

33. Beck AT, Ward CH, Mendelson M, Mock J, Erbaugh J. An inventory for measuring depression. Arch Gen Psychiatry 1961;4:561-571.

34. Lee YH, Song JY. A study of the reliability and the validity of the BDI, SDS, and MMPI-D scales. Korean J Clin Psychol 1991;10:98-113.

35. Bureau CS. Child Maltreatmen 2004. U.S. Washington, DC: Goverment Printing Office; 2006.

36. Stoltenborgh M, Bakermans-Kranenburg MJ, van Ijzendoorn MH. The neglect of child neglect: a meta-analytic review of the prevalence of neglect. Soc Psychiatry Psychiatr Epidemiol 2013;48:345-355.

37. Glaser D. Emotional abuse and neglect (psychological maltreatment): a conceptual framework. Child Abuse Negl 2002;26:697-714.

38. Norman RE, Byambaa M, De R, Butchart A, Scott J Vos T. The longterm health consequences of child physical abuse, emotional abuse, and neglect: a systematic review and meta-analysis. PLoS Med 2012; 9:e1001349.

39. Wright MO, Crawford E, Del Castillo D. Childhood emotional maltreatment and later psychological distress among college students: the mediating role of maladaptive schemas. Child Abuse Negl 2009;33:59-68.

40. Hanson JL, Hariri AR, Williamson DE. Blunted ventral striatum development in adolescence reflects emotional neglect and predicts depressive symptoms. Biol Psychiatry 2015;78:598-605.

41. O'Mahen HA, Karl A, Moberly N, Fedock G. The association between childhood maltreatment and emotion regulation: two different mechanisms contributing to depression? J Affect Disord 2015;174:287-295.

42. Wilson HW, Widom CS. The role of youth problem behaviors in the path from child abuse and neglect to prostitution: a prospective examination. J Res Adolesc 2010;20:210-236.

43. Currie J, Widom CS. Long-term consequences of child abuse and neglect on adult economic well-being. Child Maltreat 2010;15:111-120.

44. Bifulco A, Moran PM, Ball C, Lillie A. Adult attachment style. II: Its relationship to psychosocial depressive-vulnerability. Soc Psychiatry Psychiatr Epidemiol 2002;37:60-67.

45. Van Dorn R, Volavka J, Johnson N. Mental disorder and violence: is there a relationship beyond substance use? Soc Psychiatry Psychiatr Epidemiol 2012;47:487-503.

46. Slade EP, Wissow LS. The influence of childhood maltreatment on adolescents' academic performance. Econ Educ Rev 2007;26:604-614.

47. Leiter J, Johnsen MC. Child maltreatment and school performance declines: an event-history analysis. Am Educ Res J 1997;34:563-589.

48. Kavanaugh B, Holler K. Brief report: neurocognitive functioning in adolescents following childhood maltreatment and evidence for underlying planning \& organizational deficits. Child Neuropsychol 2015;21:840-848.

49. Tanaka M, Georgiades K, Boyle MH, MacMillan HL. Child maltreat- ment and educational attainment in young adulthood: results from the Ontario Child Health Study. J Interpers Violence 2015;30:195-214.

50. Bernstein DP, Flink I. Childhood Trauma Questionnaire. A Retrospective Self-Report. Manual. San Antonio, TX: The Psychological Corporation, Harcourt Brace \& Company; 1998.

51. Jud A, Fegert JM, Finkelhor D. On the incidence and prevalence of child maltreatment: a research agenda. Child Adolesc Psychiatry Ment Health 2016;10:17.

52. Iffland B, Brahler E, Neuner F, Hauser W, Glaesmer H. Frequency of child maltreatment in a representative sample of the German population. BMC Public Health 2013;13:980.

53. Heim C, Wagner D, Maloney E, Papanicolaou DA, Solomon L, Jones JF, et al. Early adverse experience and risk for chronic fatigue syndrome: results from a population-based study. Arch Gen Psychiatry 2006;63: 1258-1266.

54. Heim C, Nater UM, Maloney E, Boneva R, Jones JF, Reeves WC. Childhood trauma and risk for chronic fatigue syndrome: association with neuroendocrine dysfunction. Arch Gen Psychiatry 2009;66:72-80.

55. Scher CD, Forde DR, McQuaid JR, Stein MB. Prevalence and demographic correlates of childhood maltreatment in an adult community sample. Child Abuse Negl 2004;28:167-180.

56. Stoltenborgh M, van Ijzendoorn MH, Euser EM, Bakermans-Kranenburg MJ. A global perspective on child sexual abuse: meta-analysis of prevalence around the world. Child Maltreat 2011;16:79-101.

57. Stoltenborgh M, Alink LR, Bakermans-Kranenburg MJ, van Ijzendoorn $\mathrm{MH}$. The universality of childhood emotional abuse: a meta-analysis of worldwide prevalence. J Aggress Maltreat Trauma 2012;21:870-890.

58. Stoltenborgh M, Bakermans-Kranenburg MJ, van Ijzendoorn MH, Alink LR. Cultural-geographical differences in the occurrence of child physical abuse? A meta-analysis of global prevalence. Int J Psychol 2013;48:81-94.

59. Masten AS, Best KM, Garmezy N. Resilience and development: Contributions from the study of children who overcome adversity. Dev Psychopathol 1990;2:425-444.

60. Lee TY, Cheung CK, Kwong WM. Resilience as a Positive Youth Development Construct: A Conceptual Review. Scientific World Journal 2012;2012:390450.

61. Wu G, Feder A, Cohen H, Kim JJ, Calderon S, Charney DS, et al. Understanding resilience. Front Behav Neurosci 2013;7:10.

62. Baldassin S, Alves TC, de Andrade AG, Nogueira Martins LA. The characteristics of depressive symptoms in medical students during medical education and training: a cross-sectional study. BMC Med Educ 2008;8:60.

63. Roberts LW, Warner TD, Lyketsos C, Frank E, Ganzini L, Carter D. Perceptions of academic vulnerability associated with personal illness: a study of 1,027 students at nine medical schools. Collaborative Research Group on Medical Student Health. Compr Psychiatry 2001; 42:1-15.

64. Roberts LW, Warner TD, Rogers M, Horwitz R, Redgrave G; Collaborative Research Group on Medical Student Health Care. Medical student illness and impairment: a vignette-based survey study involving 955 students at 9 medical schools. Compr Psychiatry 2005;46:229-237.

65. Brewin CR, Andrews B. Recovered memories of trauma: Phenomenology and cognitive mechanisms. Clin Psychol Rev 1998;18:949-970.

66. Romero N, Sanchez A, Vazquez C. Memory biases in remitted depression: the role of negative cognitions at explicit and automatic processing levels. J Behav Ther Exp Psychiatry 2014;45:128-135.

67. Newby JM, Moulds ML. Negative intrusive memories in depression: the role of maladaptive appraisals and safety behaviours. J Affect Disord 2010;126:147-154. 